\title{
Which is the best repair of articular-sided rotator cuff tears: a meta-analysis
}

Lin Sun ${ }^{1,2+}$, Qiang Zhang ${ }^{3 \dagger}$, Heng'an Ge $^{1}$, Yeqing Sun ${ }^{1}$ and Biao Cheng ${ }^{1 *}$

\begin{abstract}
Background: Tear conversion followed by repair and trans-tendon techniques have been widely used for partialthickness rotator cuff tears. Both of them showed favorable results with regard to the management of articular-sided partial-thickness rotator cuff tears (PTRCTs) of more than $50 \%$ thickness. However, controversy continues with the best management. This study aims to compare the clinical outcomes between the two techniques.

Methods: The PubMed, Embase, and Cochrane library databases were searched for relevant studies published before October 1, 2014. Studies that clearly reported a comparison between the two procedures were selected. The American Shoulder and Elbow Surgeons scale (ASES) and the re-tear rate were evaluated. Statistical analysis was performed using the special meta-analysis software called "Comprehensive Meta Analysis".

Results: Final meta-analysis after the full-text review included four studies about tear conversion followed by repair and seven studies about trans-tendon technique. The trans-tendon technique showed no significant difference with the tear conversion followed by repair technique with regard to the ASES scale $(P=0.69)$. But the re-tear rate $(P<0.05)$ was markedly lower in the trans-tendon technique group than the tear conversion and repair technique group.

Conclusion: In conclusion, the meta-analysis suggests that the trans-tendon technique is better than the tear conversion followed by repair technique with regard to the management of articular-sided PTRCTs of more than $50 \%$ thickness in the re-tear rate aspect.
\end{abstract}

Keywords: Partial-thickness rotator cuff tears, Articular-sided, Trans-tendon technique, Tear conversion and repair technique

\section{Introduction}

Partial-thickness rotator cuff tears (PTRCTs) may occur on the articular side, within the tendon, or on the bursal side, with the articular-sided tears being 2-3 times more common than bursal-sided tears [1, 2]. Since partialthickness tears do not have natural integrity potential and may progress to full-thickness tears, operative intervention is typically indicated for patients with persistent pain and disability symptoms, instead of failed conservative management $[1,3]$. Several techniques have been introduced for the repair of PTRCTs, including acromioplasty alone, debridement of the partial-thickness tear with or without acromioplasty, trans-tendinous repair, or

\footnotetext{
*Correspondence: cbiaob@163.com

${ }^{\dagger}$ Equal contributors

'Department of Orthopedics, Shanghai Tenth People's Hospital, Tongji University, School of Medicine, 301 Yanchang Middle Road, Shanghai 200072, China

Full list of author information is available at the end of the article
}

end of the article conversion of the lesion to a full-thickness tear followed by repair. Nowadays, the trend is to repair lesions involving more than $50 \%$ of the tendon thickness with the conversion and repair technique or transtendinous technique. The tear conversion and repair technique is a traditional method, and satisfactory clinical outcomes have been reported [3, 4]. However, others advocate the trans-tendon repair technique as the tendon integrity, native footprint, and biomechanical properties are better restored with the intact bursal-sided rotator cuff tendon $[5,6]$. Controversy continues with the best management of PTRCTs and few studies of high level of evidence exist.

The purpose of this study was to conduct a metaanalysis to compare the two techniques for treating articular-sided PTRCTs of more than $50 \%$ thickness.

C Biomed Central

(C) 2015 Sun et al.; licensee BioMed Central. This is an Open Access article distributed under the terms of the Creative Commons Attribution License (http://creativecommons.org/licenses/by/4.0), which permits unrestricted use, distribution, and reproduction in any medium, provided the original work is properly credited. The Creative Commons Public Domain Dedication waiver (http://creativecommons.org/publicdomain/zero/1.0/) applies to the data made available in this article, unless otherwise stated. 


\section{Methods}

The PubMed, Cochrane library, and Embase databases were searched independently by two investigators (QZ and LS) to retrieve relevant studies published before October 1, 2014. The search criteria "partial thickness rotator cuff tears" were used in text word searches. The "related articles" function was used to broaden the search. The reference lists of the selected articles were also manually examined to find relevant studies that were not discovered during the database searches.

We selected any studies that reported outcomes after the operation of articular-sided PTRCTs of more than $50 \%$ thickness. All titles, abstracts, and full papers of potentially relevant studies were assessed for eligibility. When several reports from the same study were published, only the most recent or informative one was included in this meta-analysis.

Inclusion criteria

1. Language: English

2. Arthroscopic repair

3. Greater than 12-month minimum follow-up

4. Follow-up examination presenting at least one of the following matched outcomes: American Shoulder and Elbow Surgeons scale (ASES) score, re-tear rate

\section{Exclusion criteria}

1. Less than 12-month minimum follow-up

2. Studies not reporting outcomes of articular-side PTRCTs of more than $50 \%$ thickness

3. Studies including open or mini-open procedures

\section{Data extraction}

The data extraction of all variables and outcomes of interest were performed independently by 2 readers (QZ and LS). Disagreements were resolved through discussion and consensus. Taking into the existence of both randomized and non-randomized studies, we considered that the methodological quality of the included studies should be assessed by the Quality Index. The Quality Index, which consisted of 27 items distributed between five sub-scales, was appropriate for assessing both randomized and non-randomized studies [7]. Matched outcomes were checked throughout the papers. The ASES scale and re-tear rate were the matched outcome and were extracted from all the studies included. In addition, we extracted data on clinical design, country of study, number of participants, and mean follow-up. If articles reported insufficient data, we contacted corresponding authors for additional information.

\section{Statistical analysis}

The statistical analysis was performed using the metaanalysis software called "Comprehensive Meta Analysis". Continuous values (the ASES scores) was calculated by comparing their means ( $t$ test). The re-tear rate was compared by $\chi^{2}$ test. All of the effect sizes were calculated using a random-effects model. Scores (baseline to follow-up) were compared by calculating the standard difference of the means (SDM). All of the results were presented as forest plots. A $95 \%$ confidence interval was given for each effect size. Heterogeneity is expressed as $I^{2}$. This value ranges from $0 \%$ (complete consistency) to $100 \%$ (complete inconsistency).

\section{Results}

\section{Literature search}

The initial literature search retrieved 459 relevant articles (duplicates were discarded). Four hundred thirty articles were excluded for not investigating the topic of interest after carefully screening the titles and abstracts. Then, full publication review was performed, and 20 articles were excluded (4 laboratory studies, 3 reviews, 5 studies of bursal-sided PTRCTs, 2 technical note, 6 studies for not containing matched outcomes, such as the ASES scores and re-tear rate), which left 9 studies for this meta-analysis [4, 7-14]. Final meta-analysis after the full-text review included four studies about tear conversion followed by repair technique and seven studies about trans-tendon technique. Five of the trans-tendon techniques showed the medial row only with one or two suture anchors, and the other two described the medial row combined with pushlock anchors lateral to the greater tuberosity. Flowcharts describing the study selection are in Fig. 1.

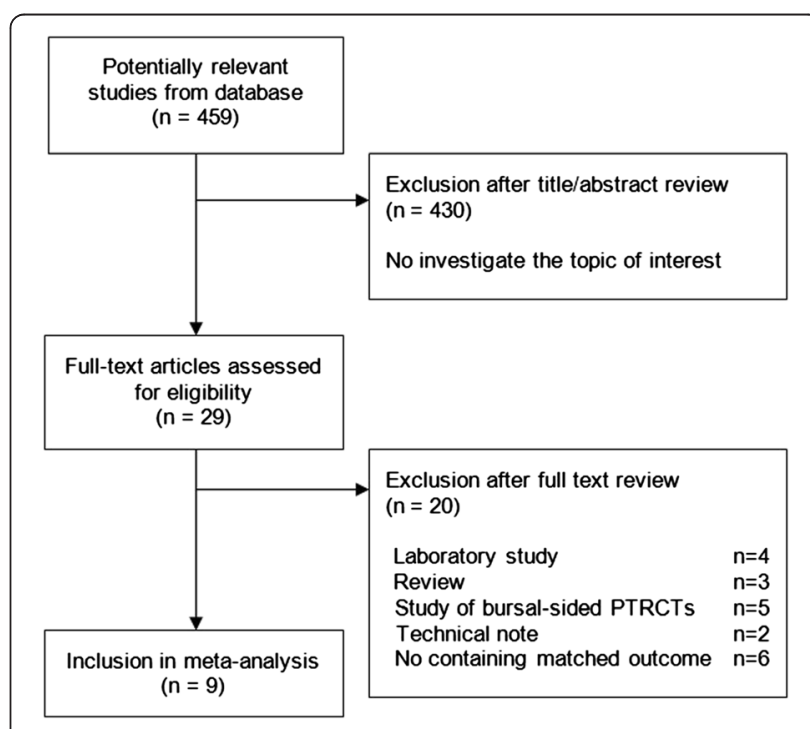

Fig. 1 Search strategy flow diagram 
Table 1 The characteristics of the included studies

\begin{tabular}{|c|c|c|c|c|c|c|c|c|c|c|}
\hline Study & Year & Country & Study design & Patients & Intervention & $\begin{array}{l}\text { Sample } \\
\text { size }\end{array}$ & $\begin{array}{l}\text { Mean } \\
\text { follow-up }\end{array}$ & $\begin{array}{l}\text { Mean } \\
\text { age }\end{array}$ & $\begin{array}{l}\text { Gender } \\
\text { (male/female) }\end{array}$ & $\begin{array}{l}\text { Matching outcome } \\
\text { measures }\end{array}$ \\
\hline Allen Deutsch & 2007 & USA & $\begin{array}{l}\text { Prospective } \\
\text { cohort study }\end{array}$ & Articular side partial-thickness rotator cuff tears (>50 \%) & $\mathrm{TCaR}$ & 33 & 38 months & 48 & $22 / 11$ & ASES \\
\hline Castricini R & 2009 & Italy & $\begin{array}{l}\text { Retrospectively } \\
\text { cohort study }\end{array}$ & Articular side partial-thickness rotator cuff tears (>52 \%) & $T T R$ & 31 & 33 months & 53.3 & $16 / 15$ & Re-tear rate \\
\hline Jaideep J. Iyengar & 2010 & USA & $\begin{array}{l}\text { Retrospectively } \\
\text { cohort study }\end{array}$ & Articular side partial-thickness rotator cuff tears (>52 \%) & TCaR & 14 & 24 months & 57.5 & Unclear & Re-tear rate \\
\hline Young-Jin Seo & 2011 & Korea & $\begin{array}{l}\text { Prospective } \\
\text { cohort study }\end{array}$ & Articular side partial-thickness rotator cuff tears (>50 \%) & TTR & 24 & 12 months & 51 & $14 / 10$ & ASES \\
\hline Sang-Jin Shin & 2012 & Korea & $\mathrm{RCT}$ & Articular side partial-thickness rotator cuff tears (>50 \%) & $T T R$ & 24 & 31 months & 53 & $10 / 14$ & ASES, Re-tear rate \\
\hline Sang-Jin Shin & 2012 & Korea & RCT & Articular side partial-thickness rotator cuff tears (>50 \%) & $\mathrm{TCaR}$ & 24 & 31 months & 57 & $13 / 11$ & ASES, Re-tear rate \\
\hline Xavier A. Duralde & 2012 & USA & $\begin{array}{l}\text { Retrospectively } \\
\text { cohort study }\end{array}$ & Articular side partial-thickness rotator cuff tears (>50 \%) & $T T R$ & 50 & 38 months & 48.7 & Unclear & ASES \\
\hline Kyung Cheon Kim & 2013 & Korea & $\begin{array}{l}\text { Prospective } \\
\text { cohort study }\end{array}$ & Articular side partial-thickness rotator cuff tears (>50 \%) & $T T R$ & 32 & 17.4 months & 51.8 & $16 / 16$ & ASES \\
\hline Francesco Franceschi & 2013 & Italy & RCT & Articular side partial-thickness rotator cuff tears (>50 \%) & $\mathrm{TCaR}$ & 28 & 39 months & 55.6 & $13 / 15$ & ASES, Re-tear rate \\
\hline Francesco Franceschi & 2013 & Italy & RCT & Articular side partial-thickness rotator cuff tears (>50 \%) & $T T R$ & 32 & 38 months & 57.3 & $18 / 14$ & ASES, Re-tear rate \\
\hline Sung-Jae Kim & 2013 & Korea & Case-control study & Articular side partial-thickness rotator cuff tears (>50 \%) & $T T R$ & 29 & 24 months & 59.1 & $10 / 19$ & ASES, Re-tear rate \\
\hline
\end{tabular}

TCaR tear conversion and repair, $T R$ trans-tendon repair 
Table 2 The methodological quality of the included studies

\begin{tabular}{|c|c|c|c|c|c|c|c|c|c|}
\hline Item & $\begin{array}{l}\text { Deutsch } \\
2007\end{array}$ & $\begin{array}{l}\text { Kim } \\
2013 \\
\end{array}$ & $\begin{array}{l}\text { Franceschi } \\
2013\end{array}$ & $\begin{array}{l}\text { Kim } \\
2013 \\
\end{array}$ & $\begin{array}{l}\text { Duralde } \\
2012\end{array}$ & $\begin{array}{l}\text { Shin } \\
2012\end{array}$ & $\begin{array}{l}\text { Seo } \\
2011\end{array}$ & $\begin{array}{l}\text { lyengar } \\
2010\end{array}$ & $\begin{array}{l}\text { Castricini } \\
2009\end{array}$ \\
\hline 1) Is the hypothesis/aim/objective of the study clearly described? & Y & Y & $\mathrm{Y}$ & $\mathrm{Y}$ & Y & $\mathrm{Y}$ & $\mathrm{Y}$ & $\mathrm{Y}$ & $\mathrm{Y}$ \\
\hline $\begin{array}{l}\text { 2) Are the main outcomes to be measured clearly described in the } \\
\text { Introduction or Method's section? }\end{array}$ & Y & Y & Y & Y & Y & Y & Y & Y & Y \\
\hline $\begin{array}{l}\text { 3) Are the characteristics of the patients included in the study clearly } \\
\text { described? }\end{array}$ & Y & Y & Y & Y & N & Y & $\mathrm{N}$ & Y & N \\
\hline 4) Are the interventions of interest clearly described? & N & Y & Y & N & N & Y & $\mathrm{N}$ & $\mathrm{N}$ & $\mathrm{N}$ \\
\hline $\begin{array}{l}\text { 5) Are the distributions of principal confounders in each group of } \\
\text { subjects to be compared clearly described? }\end{array}$ & N & N & N & N & N & $\mathrm{N}$ & $\mathrm{N}$ & N & N \\
\hline 6) Are the main findings of the study clearly described? & Y & Y & Y & Y & Y & Y & Y & Y & Y \\
\hline $\begin{array}{l}\text { 7) Does the study provide estimates of the random variability in the } \\
\text { data for the main outcomes? }\end{array}$ & N & Y & Y & Y & Y & Y & Y & Y & Y \\
\hline $\begin{array}{l}\text { 8) Have all important adverse events that may be a consequence of } \\
\text { the intervention been reported? }\end{array}$ & N & N & N & N & N & N & N & N & $\mathrm{N}$ \\
\hline 9) Have the characteristics of patients lost to follow-up been described? & Y & Y & Y & Y & Y & Y & Y & Y & Y \\
\hline $\begin{array}{l}\text { 10) Have actual probability values been reported (e.g., } 0.035 \text { rather } \\
\text { than }<0.05 \text { ) for the main outcomes except where the probability value } \\
\text { is less than } 0.001 \text { ? }\end{array}$ & Y & Y & Y & Y & Y & Y & Y & Y & Y \\
\hline $\begin{array}{l}\text { 11) Were the subjects asked to participate in the study representative } \\
\text { of the entire population from which they were recruited? }\end{array}$ & $U$ & $U$ & $U$ & $U$ & $U$ & U & $U$ & $U$ & U \\
\hline $\begin{array}{l}\text { 12) Were those subjects who were prepared to participate representative } \\
\text { of the entire population from which they were recruited? }\end{array}$ & U & U & $U$ & $U$ & $U$ & $U$ & $U$ & $U$ & $U$ \\
\hline $\begin{array}{l}\text { 13) Were the staff, places, and facilities where the patients were treated } \\
\text { representative of the treatment the majority of patients receive? }\end{array}$ & $U$ & $U$ & $U$ & $U$ & $U$ & $U$ & $U$ & $U$ & $U$ \\
\hline $\begin{array}{l}\text { 14) Was an attempt made to blind study subjects to the intervention } \\
\text { they have received? }\end{array}$ & $N$ & $N$ & $U$ & $N$ & $N$ & $U$ & $N$ & $\mathrm{~N}$ & $\mathrm{~N}$ \\
\hline $\begin{array}{l}\text { 15) Was an attempt made to blind those measuring the main outcomes } \\
\text { of the intervention? }\end{array}$ & $N$ & $N$ & $Y$ & $N$ & $N$ & $Y$ & $N$ & $N$ & $N$ \\
\hline $\begin{array}{l}\text { 16) If any of the results of the study were based on "data dredging", } \\
\text { was this made clear? }\end{array}$ & $Y$ & $Y$ & $Y$ & $Y$ & $Y$ & $Y$ & $Y$ & $Y$ & $Y$ \\
\hline $\begin{array}{l}\text { 17) In trials and cohort studies, do the analyses adjust for different lengths of } \\
\text { follow-up of patients, or in case-control studies, is the time period between } \\
\text { the intervention and outcome the same for cases and controls? }\end{array}$ & $N$ & $Y$ & $N$ & $N$ & $N$ & $N$ & $Y$ & $N$ & $N$ \\
\hline 18) Were the statistical tests used to assess the main outcomes appropriate? & Y & Y & Y & Y & Y & Y & Y & Y & Y \\
\hline 19) Was compliance with the intervention/s reliable? & Y & Y & Y & Y & Y & Y & Y & Y & Y \\
\hline 20) Were the main outcome measures used accurate (valid and reliable)? & Y & Y & Y & Y & Y & Y & Y & Y & Y \\
\hline $\begin{array}{l}\text { 21) Were the patients in different intervention groups (trials and cohort } \\
\text { studies) or were the cases and controls (case-control studies) recruited } \\
\text { from the same population? }\end{array}$ & N & Y & Y & $N$ & N & Y & N & $\mathrm{N}$ & $\mathrm{N}$ \\
\hline $\begin{array}{l}\text { 22) Were study subjects in different intervention groups (trials and } \\
\text { cohort studies) or were the cases and controls (case-control studies) } \\
\text { recruited over the same period of time? }\end{array}$ & N & Y & Y & $\mathrm{N}$ & N & Y & $\mathrm{N}$ & $\mathrm{N}$ & N \\
\hline 23) Were study subjects randomized to intervention groups? & N & N & Y & N & N & Y & $\mathrm{N}$ & N & N \\
\hline $\begin{array}{l}\text { 24) Was the randomized intervention assignment concealed from both } \\
\text { patients and health care staff until recruitment was complete and irrevocable? }\end{array}$ & $\mathrm{N}$ & N & $U$ & N & N & U & N & N & $\mathrm{N}$ \\
\hline $\begin{array}{l}\text { 25) Was there adequate adjustment for confounding in the analyses } \\
\text { from which the main findings were drawn? }\end{array}$ & N & $\mathrm{N}$ & $\mathrm{N}$ & N & N & $\mathrm{N}$ & $\mathrm{N}$ & $\mathrm{N}$ & $\mathrm{N}$ \\
\hline 26) Were losses of patients to follow-up taken into account? & N & N & $\mathrm{N}$ & N & N & Y & Y & Y & $\mathrm{N}$ \\
\hline $\begin{array}{l}\text { 27) Did the study have sufficient power to detect a clinically important } \\
\text { effect where the probability value for a different being due to chance } \\
\text { is less than } 5 \% \text { ? }\end{array}$ & 0 & 0 & 0 & 0 & 0 & 0 & 0 & 0 & 0 \\
\hline Score & 10 & 15 & 16 & 11 & 10 & 17 & 12 & 12 & 10 \\
\hline
\end{tabular}

$Y$ yes, $N$ No, $U$ unable to determine 
A total of 323 patients (99 for tear conversion and 224 for trans-tendon) were enrolled in the studies. The key characteristics of the included studies are summarized in Table 1. All the studies involved patients with articularsided PTRCTs of more than $50 \%$ thickness. Among the included studies, seven studies investigated the ASES scale and five studies investigated re-tear rate.

Table 2 summarizes the methodological quality of the included studies. The mean score of the nine studies' methodological quality was 12.55 . Two studies were RCTs with a relatively high score. The prospective cohort study, retrospectively cohort study, and case control study were included, and they got lower scores.

\section{Main analysis}

Figures 2 and 3 summarize the outcomes of the main meta-analysis. With regard to the ASES scale, no statistical difference was found between the Tear Conversion and Repair $(\mathrm{TCaR})$ technique $($ mean $=89.503,95 \% \mathrm{CI}$ 86.480-92.525) and the Trans-Tendon Repair (TTR) technique $($ mean $=88.722,95 \%$ CI 86.507-90.937) $(P=0.69$, Fig. 2). Significant heterogeneity was found between the groups $(P=0.025)$, so the random effect model was used.

With regard to the re-tear rate comparison, TCaR technique (mean $=0.113,95 \%$ CI $0.051-0.231$ ) was statistical higher than the TTR technique (mean $=0.043,95$ \% CI 0.016-0.111) $(P<0.05$, Fig. 3). No significant heterogeneity was found between the groups $(P=0.129)$, so the fixed effect model was used.

\section{Publication bias}

The funnel plots demonstrated no visual evidence of publication bias.

\section{Discussion}

Partial-thickness tears of the rotator cuff happened commonly, with the potential to cause significant pain and disability. In the older patient population, tears typically occur on the articular side of the supraspinatus tendon, near its insertion onto the greater tuberosity. Biomechanical studies have shown that in the presence of a partial-thickness tear, the strain patterns within the remaining intact rotator cuff are altered, potentially predisposing the tissue to tear propagation [15-18]. Clinical evidence also show the progression of partial-thickness tears [19]. As a result, surgery is usually needed. New techniques such as acromioplasty alone and arthroscopic debridement with or without acromioplasty have made it successful to release pain and improve the function of the patients. As the development of surgical treatments, two repair methods were mostly employed, the transtendon technique and the repair after the tear completions. The clinical outcomes of these techniques in respective articles were various, making it difficult to define the most appropriate management for PTRCTs.

In general, the technique used for the repair of these tears involves completion of the tear, followed by rotator cuff repair [20, 21]. Tear completion to full thickness creates an advantageous healing milieu that is akin to an acute full-thickness tear [5]. Although this can lead to good results, completion of the tear potentially excises normal tissue. After this tissue is excised, the normal tissue margin must be brought over and repaired to a lateral bone bed. This can alter the normal footprint of the rotator cuff, remove the degenerative tissue which probably improves tendon-bone healing, and may potentially create a length-tension mismatch of the repaired rotator cuff muscles [6]. Advances in the techniques of arthroscopic repair have led to partially torn rotator cuff repair without tear completion [5, 22-25]. The aim of such trans-tendon techniques is to preserve the lateral bursalside layer intact and to restore the footprint of the rotator cuff, thus avoiding completion of the tear, followed by cuff repair. Convincing results regarding the improvement of shoulder function and pain relief led to the

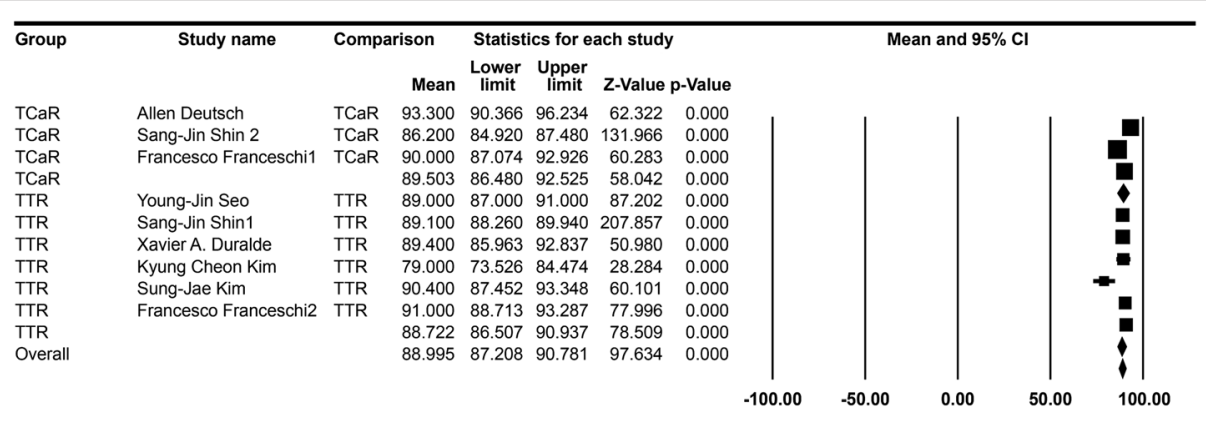

Meta Analysis

Fig. 2 Difference of the ASES scale: the forest plots present the mean ASES score of each study. Each square represents the individual study's mean score with a $95 \% \mathrm{Cl}$ indicated by the horizontal lines. Number of included studies: TCaR, $n=3 ;$ TTR, $n=6$. Mean TCaR, 89.503; TTR, 88.722. Heterogeneity $\left(P^{2}\right): \mathrm{TCaR}=45.573, \mathrm{TTR}=39.308$. Significance: $P=0.69$ 


\section{Meta Analysis}

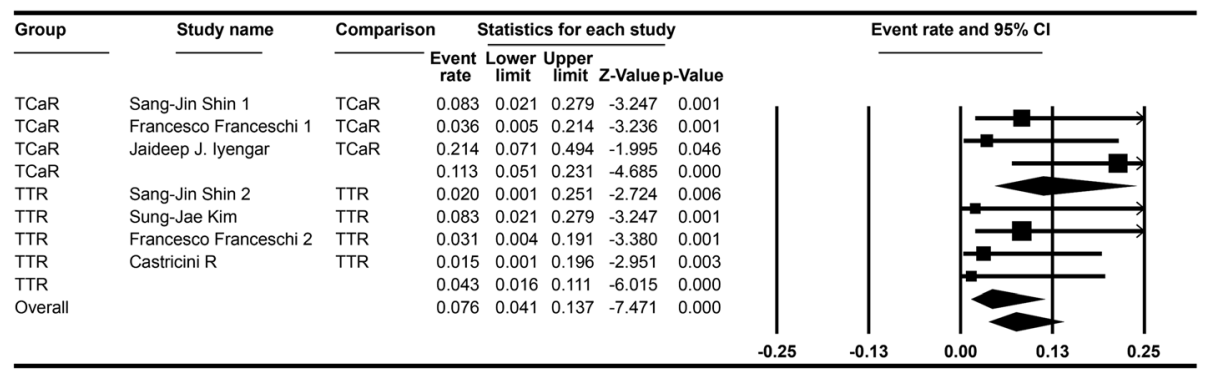

Meta Analysis

Fig. 3 Difference of the re-tear rate: the forest plots present the mean re-tear rate of each study. Each square represents the individual study's mean rate with a $95 \% \mathrm{Cl}$ indicated by the horizontal lines. Number of included studies: TCaR, $n=3 ; T \mathrm{R}, n=4$. Mean TCaR, $0.105 ;$ TTR, 0.043. Heterogeneity $\left(P^{2}\right): T C a R=34.3, T T R=0$. Significance: $P<0.001$

establishment of these arthroscopic reconstruction techniques. Cadaveric studies also have shown that preservation of the intact rotator cuff tendon provides better biomechanical properties $[15,26]$. However, these techniques, pulling a retracted articular layer onto the original footprint may overtighten the bursal aspect and consequently unbalance the tension in the remaining fibers, which may induce faster healing process [9].

The clinical outcomes (such as the ASES score, re-tear rate, and so on) were the most commonly methods to assess the surgical procedure. The above studies expounded the advantages of their own surgical procedure and showed excellent outcomes. Seldom studies with high level of evidence existed regarding the most appropriate surgical procedure of articular-sided partialthickness rotator cuff tears. With the present metaanalysis, we are able to distinguish that, if there is superiority between the two techniques. In our study, there was no significant difference between the two techniques for the ASES. But there was a significantly lower re-tear rate of the trans-tendon repair technique than tear conversion and repair technique. Therefore, the trans-tendon repair technique showed a trend towards superior outcomes in the re-tear rate aspect with regard to the management of articular-sided partialthickness rotator cuff tears (PTRCTs) of more than $50 \%$ thickness. However, it was interesting to find that patients treated by trans-tendon repair had more pain and slower shoulder functional improvements during the recovery period despite complete integrity [13]. It needed further researches to confirm this speculation.

Nevertheless, some limitations exist in this metaanalysis. Firstly, only two RCTs (that including both surgical procedures) are included in this study. Other studies' quality is not as high as the RCTs. Secondly, there are many other modified trans-tendon repair techniques, which is expected to enhance healing condition for repaired tendon. This study did not distinguish among the modified trans-tendon repair techniques which may be able to present better outcomes than tear conversion and repair technique. Lastly, many other clinical outcomes, which can assess the surgical procedures, are not considered in this study.

Although there were many limitations in this metaanalysis, it still can be used to guide future clinical work.

\section{Conclusion}

In conclusion, the meta-analysis suggests that the transtendon technique is better than the tear conversion followed by repair technique with regard to the management of articular-sided partial-thickness rotator cuff tears (PTRCTs) of more than $50 \%$ thickness in the retear rate aspect.

\section{Supporting information}

Completed Preferred Reporting Items for Systematic Reviews and Meta-Analyses (PRISMA) checklist. Additional file 1: Table S1 presents the completed PRISMA checklist for the meta-analysis.

\section{Additional file}

Additional file 1: Table S1. The completed PRISMA checklist for the meta-analysis.

\section{Competing interests}

The authors declare that they have no competing interests.

\section{Authors' contributions}

LS participated in its literature research and statistical analysis and helped to draft the manuscript. QZ participated in its design and coordination,

literature research, and helped to draft the manuscript. HG participated in its literature research and statistical analysis. YS participated in its literature research and statistical analysis. BC conceived of the study, participated in its design and coordination and statistical analysis, and helped to draft the manuscript. All authors read and approved the final manuscript. 


\section{Author details}

'Department of Orthopedics, Shanghai Tenth People's Hospital, Tongji University, School of Medicine, 301 Yanchang Middle Road, Shanghai 200072, China. ${ }^{2}$ First Clinical Medical College, Nanjing Medical University, Nanjing, China. ${ }^{3}$ Department of Orthopedics, Changzhou No. 2 People's Hospital, Nanjing Medical University, Jiangsu, China.

Received: 28 December 2014 Accepted: 15 May 2015 Published online: 28 May 2015

\section{References}

1. Fukuda $\mathrm{H}$. The management of partial-thickness tears of the rotator cuff. J Bone Joint Surg (Br). 2003:85:3-11.

2. Lehman RC, Perry CR. Arthroscopic surgery for partial rotator cuff tears. Arthroscopy. 2003;19:E81-4.

3. Weber SC. Arthroscopic debridement and acromioplasty versus mini-open repair in the management of significant partial-thickness tears of the rotator cuff. Orthop Clin North Am. 1997;28:79-82.

4. Deutsch A. Arthroscopic repair of partial-thickness tears of the rotator cuff. J Shoulder Elbow Surg. 2007;16:193-201.

5. Brockmeier SF, Dodson CC, Gamradt SC, Coleman SH, Altchek DW. Arthroscopic intratendinous repair of the delaminated partial-thickness rotator cuff tear in overhead athletes. Arthroscopy. 2008;24:961-5.

6. Lo IK, Burkhart SS. Transtendon arthroscopic repair of partial-thickness, articular surface tears of the rotator cuff. Arthroscopy. 2004:20:214-20.

7. Downs SH, Black N. The feasibility of creating a checklist for the assessment of the methodological quality both of randomised and non-randomised studies of health care interventions. J Epidemiol Community Health. 1998:52:377-84.

8. Kim SJ, Kim SH, Lim SH, Chun YM. Use of magnetic resonance arthrography to compare clinical features and structural integrity after arthroscopic repair of bursal versus articular side partial-thickness rotator cuff tears. Am J Sports Med. 2013:41:2041-7.

9. Franceschi F, Papalia R, Del Buono A, Vasta S, Costa V, Maffulli N. Articularsided rotator cuff tears: which is the best repair? A three-year prospective randomised controlled trial. Int Orthop. 2013;37:1487-93.

10. Kim KC, Shin HD, Cha SM, Park JY. Clinical outcomes after arthroscopic trans-tendon suture-bridge technique in partial-thickness articular-side rotator cuff tear. Knee Surg Sports Traumatol Arthrosc. 2013;21:1183-8.

11. Duralde XA, McClelland Jr WB. The clinical results of arthroscopic transtendinous repair of grade III partial articular-sided supraspinatus tendon tears. Arthroscopy. 2012;28:160-8.

12. Shin SJ. A comparison of 2 repair techniques for partial-thickness articularsided rotator cuff tears. Arthroscopy. 2012;28:25-33.

13. Seo YJ, Yoo YS, Kim DY, Noh KC, Shetty NS, Lee JH. Trans-tendon arthroscopic repair for partial-thickness articular side tears of the rotator cuff. Knee Surg Sports Traumatol Arthrosc. 2011;19:1755-9.

14. lyengar JJ, Porat S, Burnett KR, Marrero-Perez L, Hernandez VH, Nottage WM. Magnetic resonance imaging tendon integrity assessment after arthroscopic partial-thickness rotator cuff repair. Arthroscopy. 2011;27:306-13.

15. Mazzocca AD, Rincon LM, O'Connor RW, Obopilwe E, Andersen M, Geaney $L$, et al. Intra-articular partial-thickness rotator cuff tears: analysis of injured and repaired strain behavior. Am J Sports Med. 2008;36:110-6.

16. Andarawis-Puri N, Ricchetti ET, Soslowsky LJ. Rotator cuff tendon strain correlates with tear propagation. J Biomech. 2009;42:158-63.

17. Reilly $P$, Amis AA, Wallace AL, Emery RJ. Supraspinatus tears: propagation and strain alteration. J Shoulder Elbow Surg. 2003;12:134-8.

18. Wolff AB, Sethi P, Sutton KM, Covey AS, Magit DP, Medvecky M. Partialthickness rotator cuff tears. J Am Acad Orthop Surg. 2006;14:715-25.

19. Yamanaka K, Matsumoto T. The joint side tear of the rotator cuff. A followup study by arthrography. Clin Orthop Relat Res. 1994;304:68-73.

20. Cordasco FA, Backer M, Craig EV, Klein D, Warren RF. The partial-thickness rotator cuff tear: is acromioplasty without repair sufficient? Am J Sports Med. 2002;30:257-60.

21. Wright SA, Cofield RH. Management of partial-thickness rotator cuff tears. J Shoulder Elbow Surg. 1996;5:458-66.

22. Castricini R, Panfoli N, Nittoli R, Spurio S, Pirani O. Transtendon arthroscopic repair of partial-thickness, articular surface tears of the supraspinatus: results at 2 years. Chir Organi Mov. 2009;93 Suppl 1:S49-54.
23. Ide J, Maeda S, Takagi K. Arthroscopic transtendon repair of partial-thickness articular-side tears of the rotator cuff: anatomical and clinical study. Am J Sports Med. 2005;33:1672-9.

24. Liem D, Alci S, Dedy N, Steinbeck J, Marquardt B, Mollenhoff G. Clinical and structural results of partial supraspinatus tears treated by subacromial decompression without repair. Knee Surg Sports Traumatol Arthrosc. 2008; 16:967-72.

25. Spencer Jr EE. Partial-thickness articular surface rotator cuff tears: an allinside repair technique. Clin Orthop Relat Res. 2010;468:1514-20.

26. Gonzalez-Lomas G, Kippe MA, Brown GD, Gardner TR, Ding A, Levine WN, et al. In situ transtendon repair outperforms tear completion and repair for partial articular-sided supraspinatus tendon tears. J Shoulder Elbow Surg. 2008;17:722-8.

\section{Submit your next manuscript to BioMed Central and take full advantage of:}

- Convenient online submission

- Thorough peer review

- No space constraints or color figure charges

- Immediate publication on acceptance

- Inclusion in PubMed, CAS, Scopus and Google Scholar

- Research which is freely available for redistribution 